\title{
Transición y reformas del sector de seguridad: el rol actual de las FF.MM. en la experiencia comparada desde Argentina y Chile
}

\section{Transition and reforms of the security sector: the current role of the FF.MM. in the compared experience from Argentina and Chile}

https://doi.org/10.15332/iust.v0i15.2090

\begin{abstract}
Jean Carlo Mejía Azuero
PhD. asesor y consultor en Derecho Internacional Humanitario, Derechos Humanos y Derecho Operacional; perito Internacional ante el Sistema Interamericano; docente Universitario y profesor visitante e investigador Grupo en Estudios Políticos de la Universidad Pontificia Bolivariana de Medellín. Grupo de investigación Victus. Correo electrónico: jeanmejia3@gmail.com
\end{abstract}

Angélica Suárez Mendoza

Abogada asociada en Mejía, Ardila \& Asociados; investigadora en Derechos Humanos y candidata a magister en DD.HH. Universidad Santo Tomás Bogotá, D.C. Grupo de Investigación Victus. Correo electrónico: angelicadelpilar9@gmail.com

\begin{abstract}
Resumen
Para los fines propuestos en este artículo es esencial entender que si bien es cierto, el sector militar ha sido el eje de generación de violencia en muchas partes del mundo, este no ha sido el único, ni tampoco ha generado en todas las situaciones rupturas democráticas. Es más, el sector militar, por lo menos desde mediados de los años cuarenta se concibe con toda claridad como una columna vertebral del sostenimiento de la paz internacional (Aznar, 2011b)

Para este artículo se acudirá al estudio de la justicia de transición o justicia para la transición (Ambos, 2008 b), para explicar en términos ya específicos qué significa transición militar y seguridad, cuál es su alcance y cómo debería enfocarse. Para ello, se hará bajo la comprensión general de una transición militar, la cual puede entenderse igualmente dentro de la concepción más amplia de transiciones del Estado (ONU, 2012), entre ellas transiciones del sector seguridad (también conocidas como reformas al sector seguridad, lo que de paso incluye el término defensa (SSR)), luego de etapas de ruptura democrática o crisis democrática (O’Donell, 1997).
\end{abstract}

Palabras clave: Argentina, Chile, fuerzas armadas, guerra civil, justicia para la transición, obediencia debida, rigor militar.

\section{Abstract}

For the purposes proposed in this article it is essential to understand that while it is true the military sector has been the focus of generating violence in many parts of the world has not been the only, nor has it generated in all situations democratic ruptures. Moreover, the military, at least since the mid-forties is seen clearly as a backbone of support for international peace (Aznar, 2011b).

For this article we will go to the study of transitional justice or justice for the transition (Ambos, $2008 \mathrm{~b}$ ), to explain in specific terms what it means and military transition, what is its scope and how it should focus. And we will do so under the general understanding that a military transition which can also be understood within the broader conception of state transitions (UN, 2012), including transitions of the security sector (also known as reform of the security sector, It includes the term passing defense (SSR)) after stages of democratic rupture or democratic crisis (O’Donell, 1997). 
Keywords: Argentina, Chile, armed forces, civil war, justice for the transition, due obedience, military rigor.

\section{Résumé}

Aux fins proposées dans cet article, il est essentiel de comprendre que bien que le secteur militaire ait été l'axe de la génération de la violence dans de nombreuses parties du monde, il n'a pas été le seul et n'a pas engendré dans toutes les situations des ruptures démocratiques. De plus, le secteur militaire, au moins depuis le milieu des années 1940, a été clairement conçu comme une colonne vertébrale du maintien de la paix internationale (Aznar, 2011b).

Pour cet article, nous irons à l'étude de la justice transitionnelle ou de la justice transitionnelle (Ambos, 2008 b), pour expliquer en termes spécifiques ce que signifie la transition et la sécurité militaires, quelle est sa portée et comment elle doit être abordée. Cela se fera selon la conception générale d'une transition militaire qui peut être comprise également dans la conception plus large des transitions d'État (ONU, 2012), y compris les transitions du secteur de la sécurité (également connu sous le nom de réformes du secteur de la sécurité). En passant, il inclut le terme de défense (SSR)), après les étapes de la rupture démocratique ou de la crise démocratique (O’Donell, 1997).

Mots-clés: Argentine, Chili, forces armées, guerre civile, justice pour la transition, obéissance due, rigueur militaire. 


\section{Transición y reformas del sector de seguridad: el rol actual de las FF.MM. en la experiencia comparada desde Argentina y Chile}

Jean Carlo Mejía Azuero

Angélica Suárez Mendoza

\section{INTRODUCCIÓN}

Conceptualmente es importante tener presente que las reformas a los sectores seguridad y en concreto las enfocadas en términos del ámbito militar, pueden generarse sin que se suscite una transición, entendida desde la perspectiva de superación de un estado de violencia estructural al de construcción o profundización de una democracia (Mejía, 2015a). La forma de enfrentar nuevas amenazas a la seguridad pública puede obligar a cambios en todo un sector estatal, con el fin de cumplir los deberes constitucionales; pero es más, pueden suscitar cambios a nivel regional y mundial también, como ha sucedido con el establecimiento por parte de ONU, OEA, y Unasur de agendas relacionadas con los nuevos retos en seguridad.

Como se podrá ver a continuación en la gráfica, en la actualidad para la ONU existen seis grupos de amenazas a la seguridad pública, dentro de las que hayamos las tradicionales guerras interestatales. Igualmente, las guerras intraestatales o Conflicto Armado No Internacional - CANI, que en el concepto de la ONU son todas guerras civiles (denominación que a todas luces rechazamos porque no corresponde a una realidad mundial, que a veces desborda la concepción político-jurídica de tal organización; y porque no se compadecen con la estructuración actual de "estándares" y medidas a todas luces inaplicables a determinado tipo de violencias no generadas por los Estados, sino por la autoexclusión de un grupo humano de la democracia).

Se encuentra también un tercer grupo en el que concurre la pobreza, enfermedades infecciosas y la degradación del medio ambiente. En un cuarto grupo se haya las armas nucleares, radiológicas, químicas y biológicas. El siguiente grupo alude al terrorismo como una amenaza a la seguridad internacional $\mathrm{y}$, finalmente, se encuentran los delitos transnacionales. 


\section{METODOLOGÍA}

La metodología de este artículo será de análisis y síntesis, en tanto se busca tener pleno conocimiento sobre la transición en el sector seguridad y el rol actual de las fuerzas militares en la región, para lo cual se plantearán unas orientaciones a las reformas que se han presentado en algunos países latinoamericanos como fuente para enriquecer la experiencia que se ha llevado a cabo en sus diferentes situaciones.

Así mismo, en la recolección de información del tema objeto de este artículo se acude a distintas fuentes, de carácter normativo y doctrinal. Como es natural, también se incorpora a este análisis el bloque de constitucionalidad, así como la normatividad sustancial y procesal interna e internacional, dado que se trata de un objeto de estudio limitado a este país. Desde el punto de vista doctrinal, el análisis se centra parcialmente en análisis sobre la materia, producida, sobre todo, por instituciones, expertos u organizaciones que investigan sobre este tema, aun de manera restringida, para ampliarse al examen de las obras extranjeras que abordan el tema a profundidad.

Figura 1. Categorización de las nuevas amenazas a nivel universal

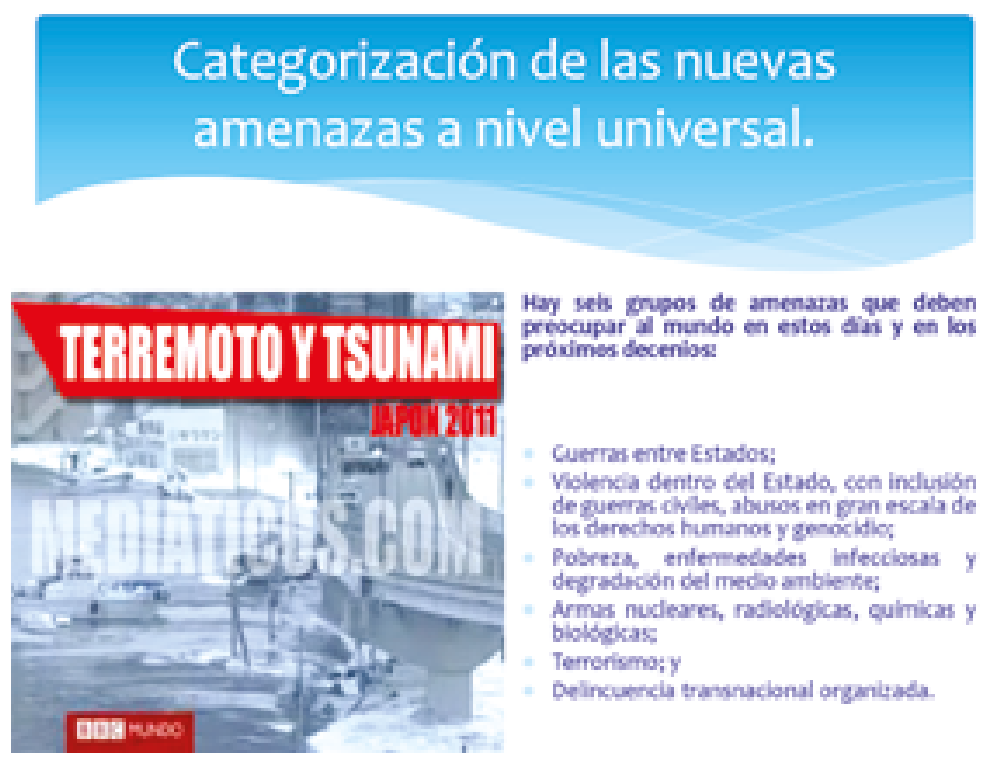

Fuente: Construcción propia. 
Ya en el contexto regional, se encuentran dos agendas relacionadas con las amenazas a la seguridad pública, una integradora en lo formal de las Américas (OEA, 2003) y una solo relacionada con Unasur (2009).

Figura 2. Nuevas amenazas a nivel regional. México 2003

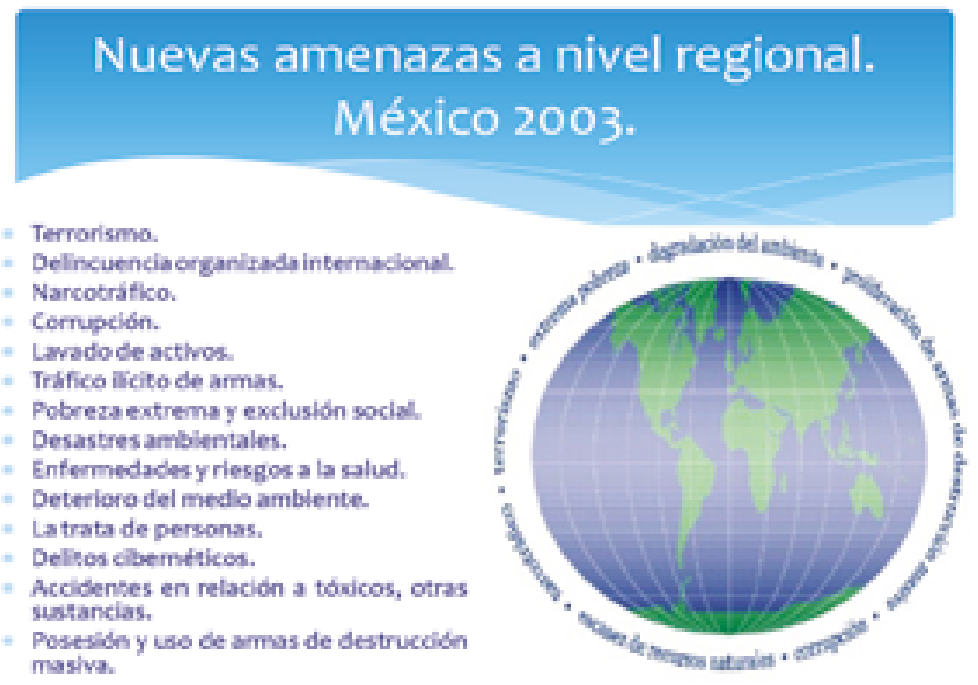

Fuente: Construcción propia.

En la conferencia especial sobre seguridad llevada a cabo en México entre el 27 y 28 de octubre del 2003, se profirió la Declaración sobre la Seguridad en las Américas y se establecieron 14 amenazas a nivel regional, casi todas con enfoque policial, pero como veremos más adelante, han conllevado la participación activa de las FF.MM. o FF.AA. para enfrentarlas adecuadamente por múltiples factores. Precisamente aquí se han necesitado reformas institucionales de fondo en el sector militar, sin que ello haya implicado transiciones militares. 
Figura 3. Nuevas amenazas para Unasur. Complejos regionales de seguridad

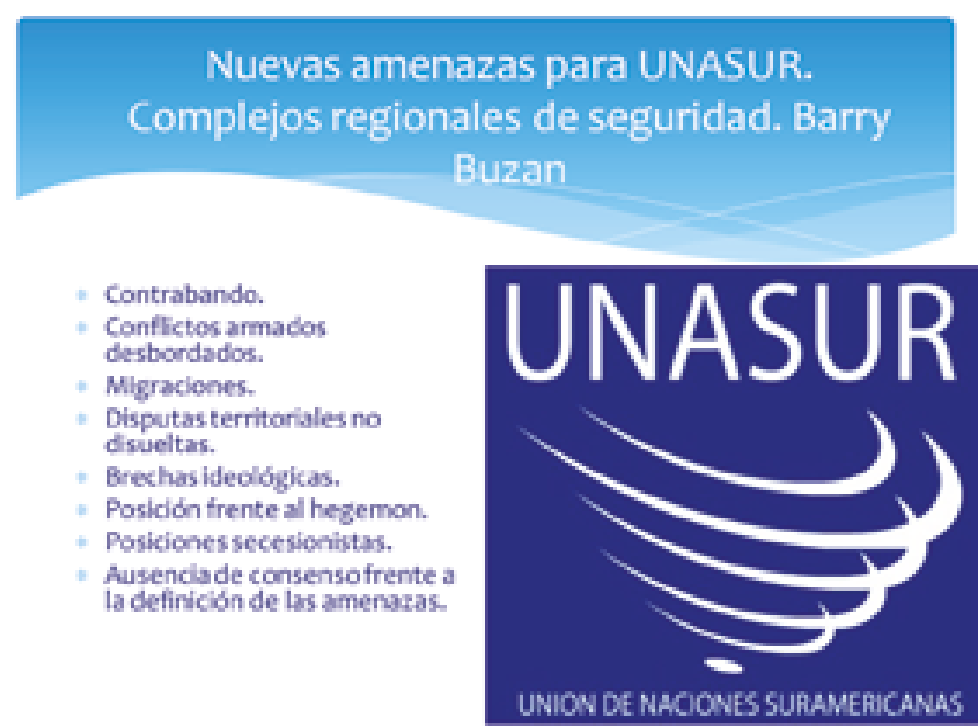

Fuente. Elaboración propia.

Finalmente, el Consejo de Defensa Suramericano de la Unasur (2009) estableció otras amenazas a la seguridad subregional con un enfoque multidimensional, en donde se incluyen temas tradicionalmente de competencia de las FF.MM. o FF.AA. y otras que ni siquiera se pueden enfrentar policialmente, sino tienen un tratamiento político y diplomático, como se ve en la gráfica, verbigracia las brechas ideológicas $\mathrm{y}$ las posiciones secesionistas.

Ahora bien, desde la perspectiva de la justicia para la transición (De Gamboa, 2006), el tema genérico de cómo enfrentar los cambios en el sector seguridad como parte del Estado, se circunscriben a lo que internacionalmente se conoce como garantías de no repetición o guarantees of non recurrence (Dugard, 1999).

De lo que se trata es de generar todo tipo de herramientas con el propósito de que no se vuelva a suscitar un contexto de violencia que implique graves violaciones a los DD.HH. y graves infracciones al DIH. Holísticamente mirado, las garantías de no repetición se constituyen en una forma de justicia, de reparación integral e incluso una medida de satisfacción para las víctimas (Acosta \& Londoño, 2015).

Cambiar, reformar, transformar puede significar también que la violencia no se repetirá. Incluso para algunos la sanción penal, con una concepción intramural retributiva puede considerarse como una garantía de no repetición (Uprimny, 2006); (Orozco, 2002). La visión holística sobre justicia transicional indicaría lo contrario, basta la imposición de la sanción y que esta sea efectiva, que además conlleve una verdad judicial; incluso a una verdad extrajudicial; que también allí se generen 
reparaciones a las víctimas concretas, entre ellas manifestaciones inequívocas de que jamás se repetirán los actos criminales, para que estemos ante un tipo de justicia transicional simétrico y no sustentado en la venganza (Elster, 1998).

Precisamente han fracasado muchos modelos de transición, pues si no hay reconciliación, el caldo de cultivo para futuras violencias, entre ellas las guerras seguirán latentes (Bass, 2000); (Berinstain, 2006); (Tapattá, 2006); (Cuéllar, 2006); (Mack, 2006); (Ames, 2006).

Los principios de lucha contra la impunidad de Joinet, actualizados y “contextualizados" por Diane Orentlicher (ONU, 2005), son una guía muy útil para ciertos contextos, pero no para todos; siendo normas del soft law deberían ser miradas como una buena práctica, y no desde la perspectiva de obligatoriedad con la cual a veces se les trasplanta; mucho más cuando conceptualmente, si bien han mejorado en su redacción, siguen mirando en blanco y negro al mundo, exclusivamente desde los DD.HH., cuando este se encuentra colmado de matices. Dentro de ese mundo de la ONU, estos principios contienen garantías de no repetición, que incluso mal trasplantadas conllevarían necesariamente violaciones a los DD.HH. (Barbosa \& Bernal, 2015). Toda una paradoja (Orentlicher, 1994).

Lo mismo podría decirse en relación con la concepción de garantías de no repetición dentro del marco del SIDH (Londoño, 2014), y especialmente desde la perspectiva de los criterios expuestos por la CORTE IDH, y las concepciones que se tengan en relación con el abordaje de reparación integral (Acosta \& Londoño, 2015, p. 103). Pues dependiendo del tipo de violencia que se quiera superar, entre ellos un CANI que no sean Guerras Civiles-GUECIV, será pertinente establecer las obligaciones internacionales, sin que exista una concepción exacerbada de control de convencionalidad (Quinche, 2014), sobre estos aspectos se gira precisamente en una de las ponencias en el presente año (Mejía, 2015b), pues no se puede seguir manteniendo la visión que las garantías de no repetición, tienen un marco de aplicación solo desde los DD.HH. (Steiner \& Uribe, 2014).

En ese sentido, para el SIDH inter alia las garantías de no repetición se constituyen de acuerdo con el artículo 63 de la $\mathrm{CADH}$, en una forma de reparación que queda en cabeza del Estado, lo que resultaría parcialmente inaplicable en casos de justicia de la transición, fruto de acuerdos de paz como en CANIS que no tengan la caracterización de GUECIV. Cristian Correa (2014) en la explicación de este artículo indica frente al tema de las garantías de no repetición:

Estas son medidas tendientes a que no vuelvan a ocurrir violaciones a los derechos humanos como las sucedidas en el caso (Corte IDH, 2001) materia de estudio ante la Corte (Corte IDH, 2001). Estas medidas tienen un alcance o repercusión pública, y en muchas ocasiones resuelven problemas estructurales, viéndose beneficiadas no solo a las víctimas del caso pero también a otros miembros y grupos de la sociedad. Las garantías de no repetición se pueden dividir a su vez en tres grupos, según su naturaleza y finalidad, a saber: a) Medidas de adecuación de la legislación interna a 
los parámetros convencionales; b) Capacitación a funcionarios públicos en derechos humanos; c) adopción de otras medidas para garantizar la no repetición de las violaciones (Correa, 2014, p. 817).

En ese sentido las víctimas de grupos al margen de la ley quedarían totalmente en desventaja en relación con aquellas víctimas generadas por agentes del Estado y que impliquen reformas institucionales. Los grupos armados ilegales tienen también que comprometerse con el otorgamiento de garantías de no repetición respecto a sus víctimas, como una forma de repararlas integralmente.

En estos escenarios el DIH no resuelve las cosas, por el contrario, se convierte en un palo en la rueda para las transiciones políticas dentro de una democracia. Y aunque el SIDH ha venido tratando de extender más allá de los casos específicos planteados dichas garantías hacía otras víctimas de violaciones masivas de los DD.HH., no se expresa nada al respecto de las graves infracciones al DIH que no pueden ser subsumidas dentro del primer ordenamiento. Hasta este punto, las pretendidas convergencias entre el DPI y el DIDH, desarrolladas por los exjueces de la Corte IDH, Cançado Trindade y García Ramírez, no llegan (Corte IDH, 2006).

En ese sentido, podría ser incluso más garantista el nuevo DPI, desde la perspectiva de los derechos de las víctimas en el Estatuto de Roma (ER), para intervenir. De acuerdo con el artículo 68, específicamente a ser reparados según el artículo 75, y teniendo en cuenta la Regla 85 del instrumento de procedimiento y pruebas, habida cuenta que tal reparación debe provenir de quien es hallado responsable penalmente (ICC, 2008).

En conclusión, habrá que establecerse de acuerdo con el contexto específico de superación de cada tipo de violencia (autoritarismos, dictaduras, guerras internacionales, guerras civiles y otros CANI), las medidas que pueden implementar los Estados y los particulares que otorguen garantías de no repetición a todas las víctimas, tanto de graves violaciones a los DD.HH. como de graves infracciones al DIH. De igual forma en virtud del sistema de justicia de transición por implementar, se podrán establecer la intensidad de las reformas sectoriales y valorar las políticas y medidas ya tomadas para evitar que se repitan las tragedias del pasado. En ese sentido, la no repetición termina siendo esencial.

Un elemento esencial para el análisis de una transición militar, desde la concepción genérica de SSR es el de verificación de lo que en la actualidad cumplen las FF.MM. o FF.AA. en el mundo. Pero para los propósitos de este artículo se situará dentro de la región, por varias razones, a saber:

1. Desde el contexto más próximo se podrá tener una referencia clara en relación con reformas y transiciones militares, que pudiera eventualmente ser aplicable a un caso como el colombiano.

2. La proyección geopolítica, geoeconómica y geoestratégica tiene una concepción o alcance regional y luego global; Colombia después de casi cien años poco ha salido del réspice polum. 
3. El continente que dio paso al concepto de "justicia transicional", es el americano, y en específico la sub región suramericana con el caso de las dictaduras militares del Cono Sur.

4. El Sistema Internacional de protección de DD.HH., más influenciado por el contexto es el americano, y de él incluso han referenciado el Sistema Europeo de Derechos Humanos (SEDH) en casos como Mamatkulov \& Askarov versus Turkey (ECHR, 2005) y la misma Corte Penal Internacional, en casos específicos como los del Congo, para ser exactos en las decisiones del caso Lubanga Dyilo (ICC, 2008).

De igual forma se han tenido en cuenta cuatro de los estados referenciados en la primera parte de este artículo, con el propósito de mirar qué ha pasado después de una etapa que se supone de consolidación democrática, luego del período transicional. Es decir, más adelante se verán en los casos de Argentina y Chile que representan la superación de dictaduras.

Lo anterior no obsta para referirse a otras situaciones de reformas y transiciones militares en concreto y en amplio del sector seguridad cuando sea menester. Las fuentes principales de descripción y análisis en este acápite serán el Atlas Comparativo de la Defensa en América Latina y el Caribe de (RESDAL, 2015); el texto sobre reforma de las Fuerzas Armadas en América Latina y el impacto de las amenazas irregulares del Woodrow Wilson Center (Perales, 2008); el texto de la ONU “The United Nations SSR Perspective" (ONU, 2012) y nuestra ponencia en el XXXIII Curso Interdisciplinario de DD.HH. en San José de Costa Rica en el 2015.

\section{ARGENTINA Y LA SITUACIÓN ACTUAL DE SUS FF.AA. ENTRE DEFENSA Y SEGURIDAD FORMAL Y LA REALIDAD}

Vale la pena recordar, de acuerdo con lo visto, en la primera parte de este artículo, que el caso argentino ha sido tomado por muchas naciones y organismos internacionales, como la ONU y la OEA, como un paradigma transicional por seguir luego de un período de dictadura militar. El contexto de masivas violaciones a los DD.HH. cometidas por miembros de las FF.AA. argentinas, suscito medidas, ora recomendadas por la Comisión Sábato, o bien legislativas o impuestas por el propio ejecutivo civil. De acuerdo con el Programa de Naciones Unidas para el Desarrollo (PNUD), la reforma militar argentina se podría definir como "abolición de la impunidad", esto en relación con las medidas tomadas para juzgar a las juntas militares, y luego derogar las leyes de punto final y obediencia debida, proferidas por los gobiernos de Alfonsín y Menem (PNUD, 2009).

Siguiendo esa concepción, podríamos sintetizar la transición militar argentina luego del año 1983, de la siguiente forma:

1. Reducción del gasto militar.

2. Abolición de la doctrina de seguridad nacional. 
3. Traspaso de las industrias militares al Ministerio de Defensa con administración civil.

4. Reforma de la inteligencia militar.

5. Subordinación militar al poder civil.

6. Desmilitarización de la seguridad interior.

7. Redefinición del concepto defensa nacional frente a amenazas externas únicamente.

8. Reforma al Código Penal Militar para casos típicamente militares.

9. Reemplazo del servicio militar obligatorio por el voluntario.

10. Educación en derechos humanos para las FF.AA.

De acuerdo con (RESDAL, 2015, p. 134) para el año 2014 la población de la Argentina era de 41.775 .000 y una extensión territorial terrestre de 2.780 .400 $\mathrm{km}^{2}$ y 77.066 militares, incluyendo las tres fuerzas. Entre los años 2008 y 2014 el presupuesto del sector descendió respecto al total de la Nación del 5.8\% al 4.08\%. El gasto de personal compromete el $60 \%$ del presupuesto del sector, seguido por el componente prestacional y un muy bajo presupuesto para la inversión; lo que es regla en toda la región.

Las FF.AA. cuentan con más de 10 leyes vigentes que regulan su actuación, que provienen desde mediados del siglo XX, como la Ley 12.709 de 1944 sobre fabricaciones militares, hasta leyes recientes como la que derogó el Código Penal Militar, modificando el Código Penal Militar que data del 2008 (26.394) y establece aspectos relacionados con la actuación militar en época de conflicto (RESDAL, 2015, p. 134).

Entre las normas sectoriales más importantes y que brindan un marco de seguridad jurídica encontramos: La Ley de defensa nacional, 23.554 de 1988, es decir, promulgada en plena transición y con los debates más fuertes entre el sector civil y el militar (ver supra). La Ley de Seguridad Interior (24059 de 1992), en la cual se concretan algunas medidas fruto del fin de la dictadura (RESDAL, 2015, p. 134). Una ley muy interesante que es la de reestructuración de las FF.AA. (24948 de 1998); y la Ley de Inteligencia Nacional que es del año 2001 (25520).

El Ministerio de Defensa Nacional de Argentina fue creado en 1958, pero desde el regreso a la democracia han pasado 35 ministros de defensa civiles, por cuatro militares, pudiendo ser las mujeres ministras como sucedió entre los años 2005 y 2010 con la ministra Garré. El sistema de Defensa se encuentra integrado estratégicamente por el Presidente que tiene dos cuerpos asesores, el Consejo de Defensa Nacional (CODENA) y el Comité de Crisis. Subordinado al presidente se encuentra el Ministro de Defensa y del él depende el Estado Mayor Conjunto de las FF.AA. Los tres estados mayores de las FF.AA. (Ejército, Marina y Fuerza Aérea) dependen directamente del Ministerio y solo en materia de planificación y conducción conjunta del Estado Mayor Conjunto (RESDAL, 2015, pp. 135). 
Figura 4. Defensa en América Latina y Caribe

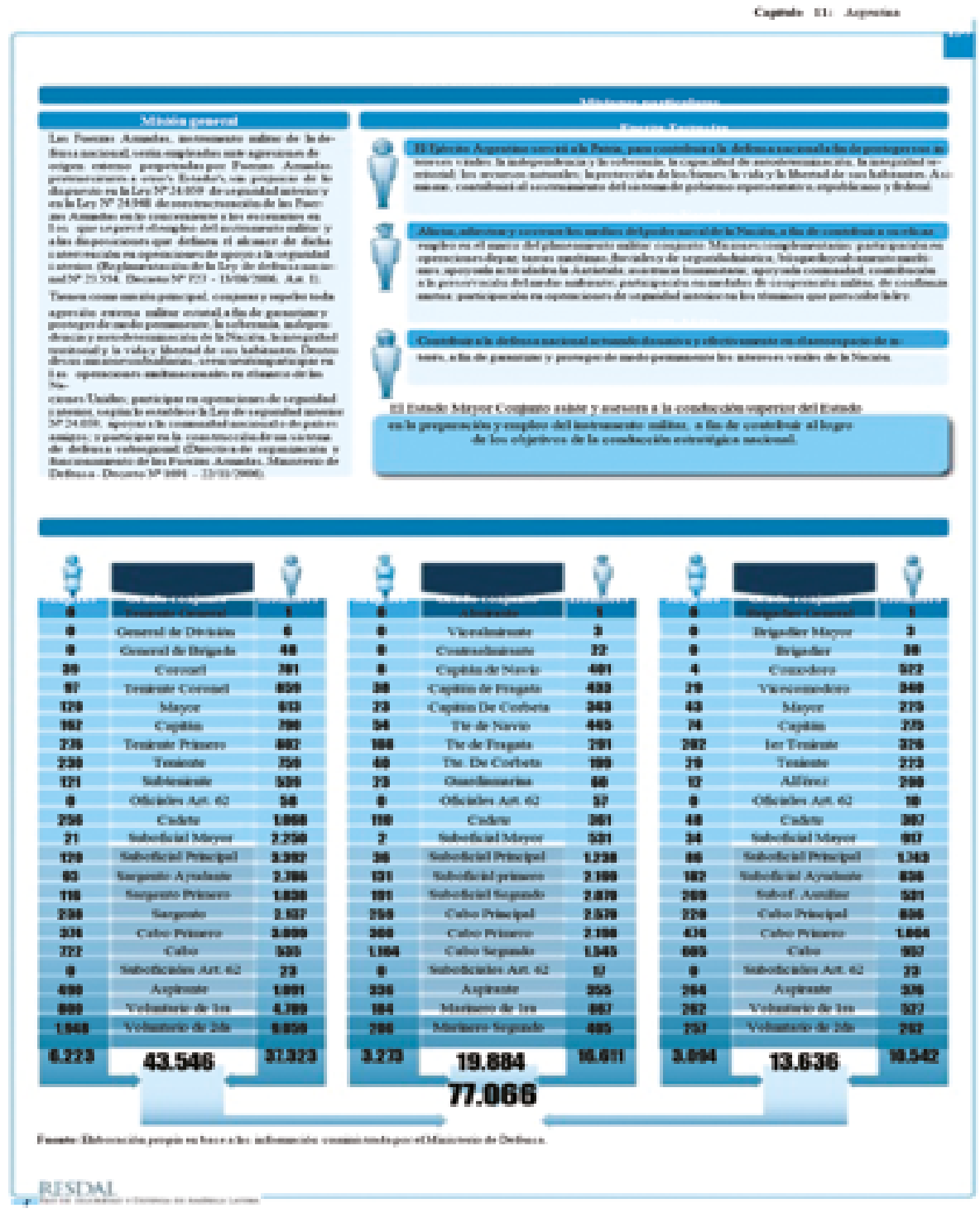

Fuente: Atlas comparativo de la defensa en América Latina y Caribe. Edición 2014, p. 137.

Del anterior cuadro podemos encontrar que serán las leyes las que establecen en Argentina la posibilidad de cumplir roles dentro de un esquema de seguridad interior o interna, de acuerdo con las previsiones que de allí se regulan. 
Así que si bien es cierto el rol clásico de las FF.AA. se sigue cumpliendo en la Argentina, vemos también nuevas posibilidades no solo de actuación a nivel nacional, sino como las mismas normas lo expresan de actuaciones en el marco internacional a través de la cooperación, como puede ser el caso de participación en fuerzas de paz, como de hecho sucede en Sahara, Haití, Chipre, Israel y Palestina con un total de 838 hombres y mujeres, lo que representa el $13.72 \%$ de lo que aportan los países de la región (RESDAL, 2015, p. 141) 1 .

Por otro lado, recientemente a través de Decreto Presidencial 836 se incorporaron nuevos roles al sector Defensa para la coordinación y despliegue de las FF.AA. en casos de desastres y para la creación del Polo Industrial y Tecnológico de Defensa, muy ligado con la agenda de Unasur, además, desde esa perspectiva integradora el Ministerio de Defensa pasó a trabajar directamente con otros sectores del ejecutivo, como desarrollo social, interior, salud, seguridad, planificación, educación y trabajo (RESDAL, 2015, p. 140).

Para Rut Diamint (2008), investigadora argentina, para el momento de escribir sobre el tema de la separación entre defensa y seguridad en la región, resultaba muy preocupante la militarización de la seguridad interior, y en gran parte ello se debía al fracaso de la consolidación de los estados latinoamericanos y sus democracias (en el mismo sentido por ejemplo (O’Donell, 1997, pp. 106 -107).

Indica que esto afortunadamente no ha sido lo mismo en el Cono Sur, principalmente en Chile, Uruguay y Argentina (Diamint, 2008, pp. 106-107); pues afortunadamente no se ha dado paso a la presión norteamericana a través de su Command Strategy 2016 para desarrollar actividades interagenciales, secularizando de paso el que considera débil Estado de derecho (p. 108). En ese sentido, y desde esta perspectiva lo compartimos, la región debería dejar de seguir siendo rule - taker y pasar a ser rule - maker.

Lo anterior, que representa graves preocupaciones, genera más trastornos al ver, como lo expresamos este año en el XXXIII Curso Interdisciplinario de DD.HH. del Instituto Interamericano de Derechos Humanos, que la realidad desborda para el 2015 la concepción de manejo de la seguridad interior (seguridad ciudadana) en la región por parte de los cuerpos de policía. La siguiente gráfica muestra la magnitud del tema, dentro de múltiples agendas políticas.

1 En el año 1995 se creó el Centro Argentino de Entrenamiento Conjunto de Operaciones de Paz (RESDAL). 


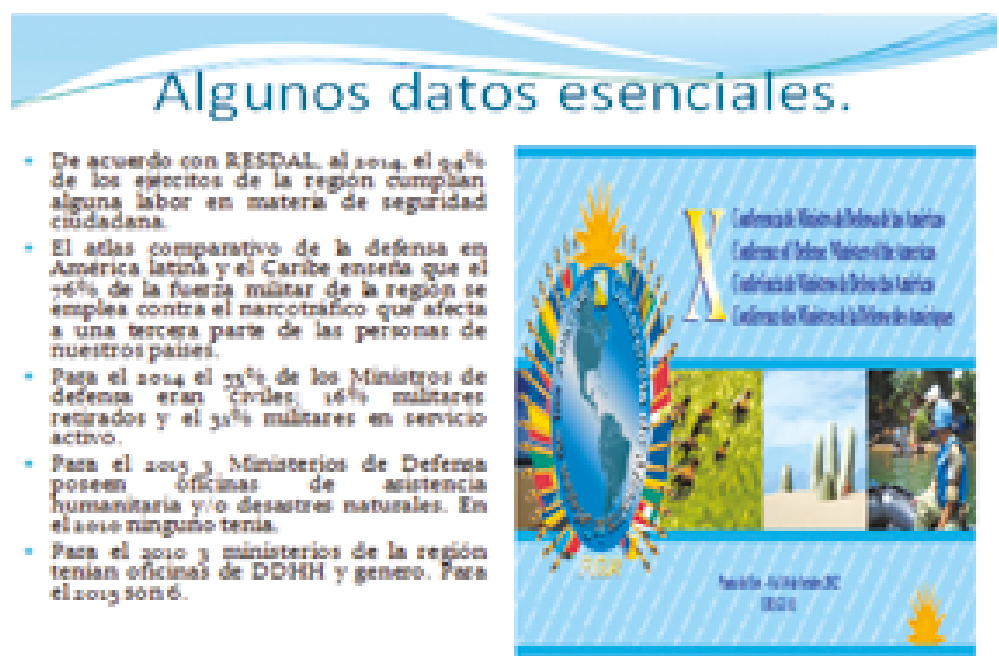

Fuente. Elaboración propia. Ponencia en el Curso XXXIII de DD.HH. IIDH 2015. 9 de septiembre del 2015. San José, Costa Rica.

En consecuencia muchas reflexiones se tienen que realizar desde la perspectiva de los roles clásicos entre defensa y seguridad (o seguridad exterior e interior), más cuando las circunstancias actuales son tan cambiantes y requieren del compromiso de todas las instancias estatales frente a amenazas que antes solo eran consideradas exclusivas de un ámbito interno.

Que el 94\% de los ejércitos de la región estén en la actualidad cumpliendo cualquier labor en términos de seguridad ciudadana o interior, es necesario estudiarlo a profundidad; que además el $76 \%$ de los mencionados ejércitos estén comprometidos en la guerra contra el narcotráfico, dice mucho también. Estos que serían roles secundarios para las FF.AA., pueden generarnos importantes elementos de comprensión de la concepción regional de los militares en el siglo XXI, cada vez más superado el miedo a los levantamientos castrenses y rupturas democráticas, salvo el caso de Honduras.

Juan Rial (RESDAL, 2015, p. 11) enseña algo que resulta a todas luces fundamental para entender hoy en día, más cuando de reformas militares se trata, estamos en presencia o no de transiciones.

En momentos de fuertes cambios en el escenario internacional, la guerra es un fenómeno en desaparición, frente a un incremento constante de la violencia. Aclaramos. La confrontación entre grandes organizaciones militares complejamente conformadas y especializadas es un hecho que cada vez es más difícil que ocurra. Los últimos grandes conflictos son asimétricos, el derrotado no presenta batalla, como ocurrió en Afganistán o Irak, y tampoco hay, como en el pasado rendiciones, o 
negociaciones formales entre el ganador y el perdedor. Muchos de los conflictos son periféricos, se desarrollan en zonas atrasadas y todos dependen cada vez más de la cobertura mediática para su desenlace.

A partir del 2011 en la Argentina, específicamente en el norte, las FF.AA. empezaron a colaborar a las autoridades policiales en la lucha contra el tráfico de estupefacientes, trata de personas y contrabando, de acuerdo con los Decretos 1091 del 2011; 2689 del 2012 y 2221 del 2013 (RESDAL, 2015). Con ello la visión de la profesora Diamint (2008), ha sido desbordada por la realidad.

\section{CHILE. EL RIGOR MILITAR Y LA OBEDIENCIA DEBIDA AL SECTOR CIVIL}

El tipo de reformas propuestas en Chile una vez terminado el gobierno Pinochet, estuvo en consonancia, como se observó en la primera parte, con las previsiones que había hecho el mando militar en la Constitución de 1980 y su reforma del año 1989. La Comisión Rettig marcó unos puntos especiales respecto a lo que sectorialmente se debería hacer, particularmente resaltando la necesidad de generar canales entre la sociedad civil y la sociedad militar. Muy diferente a lo ocurrido en la Argentina. Además las recomendaciones sobre reformas se enfocaron a:

1. Redefinir y precisar las funciones de la inteligencia.

2. Limitar las funciones de la inteligencia de las FF.AA., carabineros y otros organismos de seguridad estatal.

3. Definir y precisar una política efectiva de lucha contra el terrorismo que respetara los DD.HH.

4. Estudiar a fondo el principio de obediencia debida para que so pretexto de su aplicación no se volvieran a presentar violaciones a los DD.HH.

5. Buscar canales de comunicación entre los civiles y militares a través de la educación y la capacitación profesional.

6. Estudiar a fondo el concepto de seguridad nacional para establecer luego el tipo de reformas jurídicas a implantar (PNUD, 2009, p. 11).

El informe de (RESDAL, 2015) enseña sobre la situación de defensa de Chile para el año 2014, que este país tiene una población de 17.748.000 millones de habitantes y una extensión terrestre de $756.000 \mathrm{~km} 2$. Cuenta con un total de 59.031 miembros de las FF.AA. y un presupuesto anual de US 5.511 millones de dólares, que entre los años 2008 y 2014 representaron un incremento en el gasto de personal del $48 \%$, entre asignaciones de retiro y prestaciones sociales. A diferencia de Argentina la inversión del sector es mucho mayor (19,7\%), generalmente asociada a la Ley del Cobre (p. 160), pero mucho menor a la de Nicaragua (22,6\%), Perú $(23,3 \%)$ y Venezuela $34,3 \%)$ para el 2014 (p. 36). 
Chile cuenta con más de 25 leyes y decretos ley (con fuerza de ley) sectoriales, el $80 \%$ posteriores a la salida del gobierno militar; jurídicamente el sistema de defensa se encuentra en cabeza del presidente, en este caso la presidenta) quien cuenta con un órgano asesor denominado Consejo de Seguridad Nacional (COCENA). Al mismo nivel de la cabeza del Ministerio de Defensa Nacional se encuentra la junta de comandantes en jefe, y bajo línea de mando directa del Ministerio el Estado Mayor Conjunto. También bajo línea de mando directa del Ministerio las tres fuerzas (RESDAL, 2015, p. 160).

Chile cuenta con varias normas marco para las Fuerzas Armadas, además del libro blanco del 2010, como demostración de manejo transparente y abierto del sector. Sectorialmente se cuenta con la Ley Orgánica Constitucional de las FF.AA. 18948 de 1990, reformada en el 2014 por la 20735. Cuenta con una Ley de Planta y Tropa Profesional que es la 20303 del 2008; una curiosa Ley de Delitos de Lesa Humanidad y Crímenes de Guerra que es la 20357 del 2009 y una Ley de Inteligencia Estatal del año 2004, que es la 19974 (RESDAL, 2015, p. 160).

De acuerdo con el Estudio de la profesora Dammert (2008), las reformas al sector defensa y seguridad están ligadas al ámbito de la profundización de la profesionalización (p. 100). A diferencia de Argentina más que prevenciones respecto al sector militar y resquemores, lo que se encuentran son retos, para acercar el estamento militar al sector civil que lo dirige. En ese sentido, lo que encontramos aquí es una mayor concepción de gueto militar.

La investigadora para el centro Woodrow Wilson (Dammert, 2008), plantea seis áreas que generan retos, a saber:

1. Incrementar el poder civil en las instancias de decisión estratégico-militar, sobre todo en ámbitos como el presupuestario y en la educación militar (Dammert, 2008, pp. 100 - 101).

2. Capacitación de más personal civil en temas de seguridad y defensa.

3. Redefinición de roles y funciones ante las nuevas realidades.

4. Vinculación de tareas presupuestarías a metas y objetivos concretos.

5. Revisión del sistema de sanidad militar por su valor y eficacia.

6. Revisión de pertinencia del servicio militar obligatorio (Dammert, 2008, pp. $100-101)$.

No existe, en lo aquí descrito, ni la más leve incorporación de un discurso político - ideológico sobre el sector. Todo lo contrario, coadyuva las conclusiones sobre el mismo tema de la primera parte y respecto al mismo país. De acuerdo con RESDAL (2015), Chile es el único país en la región en donde las FF.AA. o FF.MM. no participan en ninguna labor de seguridad ciudadana o interior; salvo las previsiones excepcionales en materia de crisis humanitarias y desastres naturales. 
Imagen 6. Relaciones entre defensa y seguridad pública en el contexto regional

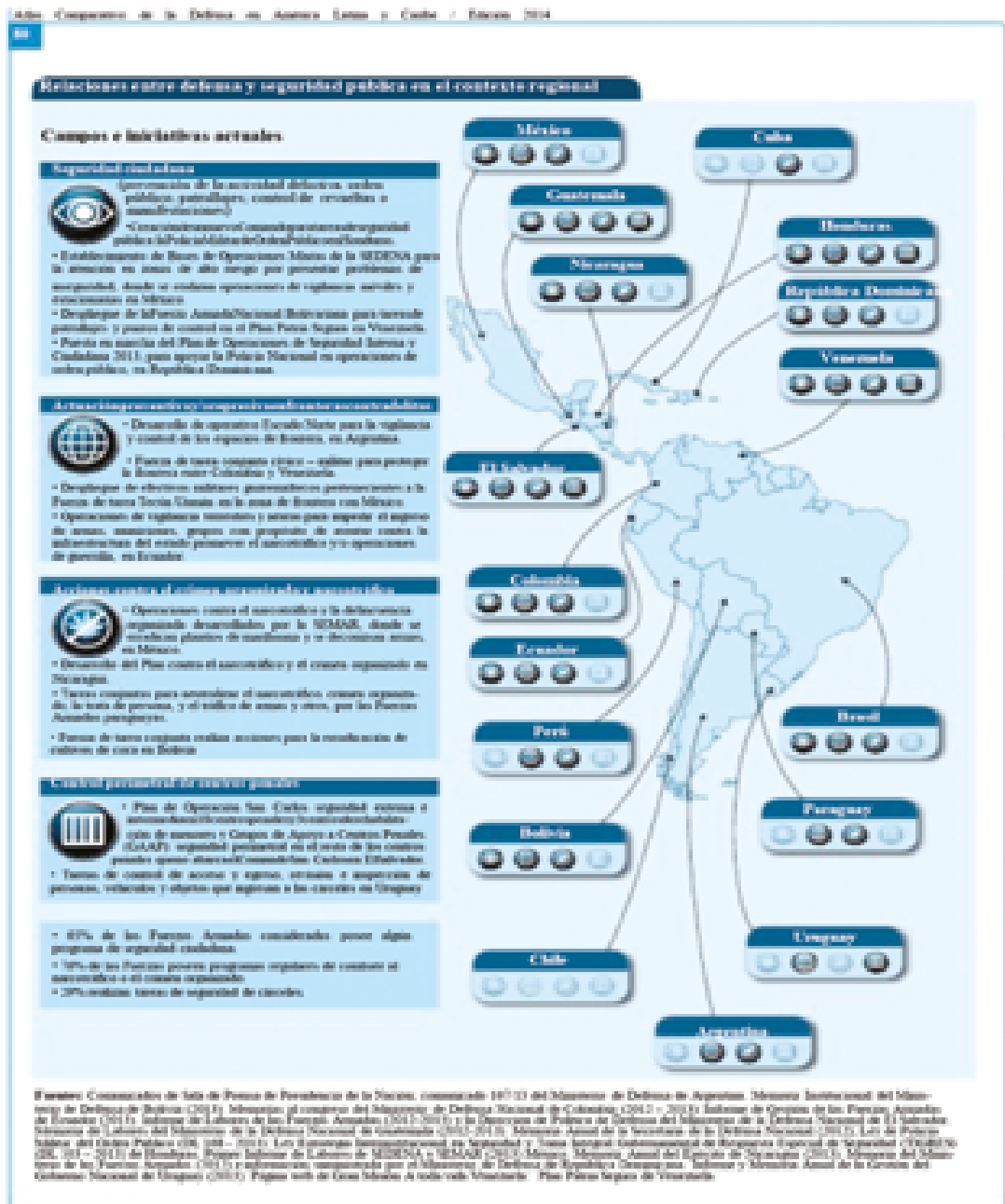

Puspal

Fuente: Atlas Comparativo de la Defensa en América Latina y Caribe, 2014, p. 80.

Se puede concluir para el caso de Chile, que si bien es cierto se ha surtido una transición hacia una democracia y una reforma militar en ámbitos puramente profesionalizantes, donde la defensa juega un papel tradicional, lentamente la agenda internacional a nivel político ha empezado a generar reflexiones en torno a la ampliación de roles para las FF.AA. chilenas, más allá de las que se coligen de su participación internacional en labores de cooperación bajo el mandato de la ONU. 
Las nuevas amenazas a la seguridad pública llevarán a Chile a profundizar el rol de sus FF.AA., seguramente como ocurrió en Argentina y Uruguay, esta fue una de las conclusiones, además del III Foro Interamericano de Justicia Militar y Derecho Operacional, llevado a cabo en Santiago y Viña del Mar entre el 19 y 21 agosto del 2015 (AGN, 2015).

La siguiente figura puede mostrar un poco mejor la múltiple interacción de agendas regionales y subregionales con diferentes intereses y propósitos, y la compleja situación que se avecina, pues a medida que se incrementan las asimetrías ligadas a las nuevas amenazas, más retraso en la práctica se presenta para contrarrestarlas a nivel interno e internacional.

Figura 7. Dificultades
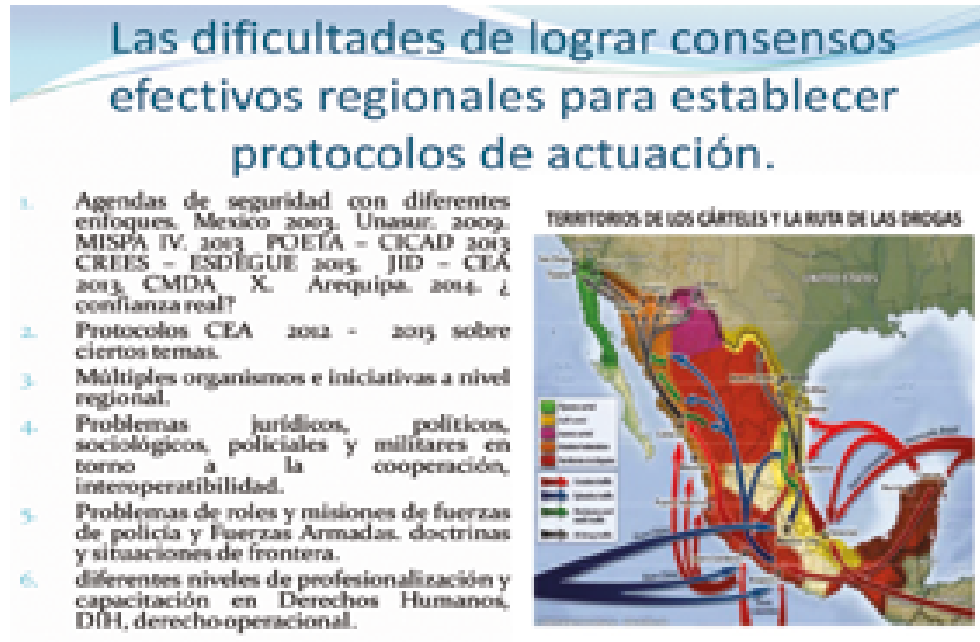

Fuente. Elaboración propia. Ponencia en el Curso XXXIII de DD.HH. IIDH, 2015.

\section{ALGUNAS CONCLUSIONES IMPORTANTES DE LAS EXPERIENCIAS ANALIZADAS}

Se encuentra que las transiciones estudiadas tienen elementos comunes y otros que las diferencian ostensiblemente. Entre los primeros se encuentra la preocupación por superar violaciones graves a los DD.HH. durante el período de violencia, lo que ha generado el desarrollo de algunos principios, acogidos como "estándares", para luchar contra la impunidad (Joinet, Orentlicher, Theo Van Boven, Cherif Bassiouni).

Los anteriores principios organizados y desarrollados por expertos de la ONU, la OEA, OCDE, no discriminan en la práctica contextos, situaciones, escenarios y evolución de variables exógenas y endógenas relacionadas con las múltiples violencias. Las consideraciones diferenciales son meramente formales. 
Un segundo elemento común de las violencias estudiadas hace alusión a la necesidad de reformas sectoriales (ONU) o de un sistema (OCDE), que incluye tanto aspectos puramente militares, como aspectos relacionados con seguridad interior, pública o como se le denomina actualmente, ciudadana. Esto para casos de superación de dictaduras, GUECIV y CANIS.

En tercer lugar, existe otro elemento común y es el relacionado con las temáticas sobre las cuales debe girar la reforma militar, sin importar el tipo de macrocriminalidad política enfrentada, trabajando temas como:

1. Presupuestos del sector y de las fuerzas.

2. Pie de fuerza una vez superado el marco de violencia.

3. Educación militar.

4. Doctrina militar.

5. Misión y roles.

6. Marco jurídico.

7. Despolitización del sector.

8. Relaciones cívico - militares y ámbito de subordinación.

9. Políticas de vetting dentro del sector, tanto militares como civiles.

10. Enfoque punitivo y penitenciario para miembros de las fuerzas de seguridad.

11. Reforma a la inteligencia estatal y a la militar.

12. Formación de líderes civiles para el control del sector defensa.

13. Intervención internacional en los procesos por parte de expertos internacionales.

14. Estudio de experiencias comparadas.

15. Trasplantes.

16. Supresión de unidades militares.

17. Justicia penal militar.

18. Servicio militar y su obligatoriedad.

19. Sistema prestacional del sector.

20. Seguridad jurídica en el tiempo. Persecución penal nacional e internacional sin límites.

21. Amnistías, indultos, leyes de punto final, autoamnistías, normas de obediencia debida.

22. Intervención de víctimas ocasionadas por las FF.AA. a través de ONG.

23. Enfoque con exclusividad en el Ejército.

24. Interpretación transversal de la denominada doctrina de seguridad nacional.

25. Veeduría internacional multinivel (ONU, OEA, OCDE, FMI, Banco Mundial).

26. Intervención del SIDH.

27. Mirada meramente formal del DIH.

28. Enfoque de violencia vertical así se esté superando una violencia horizontal.

29. Medidas implementadas por recomendaciones de comisiones de la verdad. 
30. Máximos responsables de la comisión de violaciones a los DD.HH. en las FF.AA.

31. Responsabilidad del superior; responsabilidad del mando; responsabilidad por omisión. Concepción Núremberg.

En cuarto lugar, en todos los casos estudiados los análisis generalmente se realizan desde la perspectiva de guerra fría y un contexto de influencia de los EE.UU.

Como quinta medida en todos los casos de transición militar se encuentran nuevos roles internacionales asumidos como participación de las Fuerzas Armadas en misiones de paz, especialmente dirigidas por la ONU.

En sexto lugar, en todos los casos hay un énfasis en la existencia de grupos paramilitares, escuadrones de la muerte o líneas de mando paralelas.

En todos los casos se ha presentado, luego de varios años, persecución internacional a los militares y policías acusados de graves violaciones de DD.HH., con activación plena de la jurisdicción universal o con la aplicación de la jurisdicción de un Estado para lograr indemnizaciones en casos civiles, frente a demandas de las víctimas.

En octavo orden, una concepción de "militarismo" de la sociedad civil y una necesidad de "desmilitarización de la misma".

Por último, en todos los casos se encuentra en la actualidad el uso de fuerzas armadas para dos fines claramente relacionados con la seguridad pública: desastres naturales y crisis humanitarias.

Pero igualmente existen elementos que diferencian los casos estudiados y que como se pudo observar algunas veces no son tenidos en cuenta por organismos internacionales y nacionales para establecer criterios diferenciales relacionados con SSR (Security System Reform para OCDE o Security Sector Reform para ONU) y puntualmente con lo que hemos considerado MSR (Military Sector Reform).

En primer lugar existen cuatro concepciones de violencia diferentes. Una dictadura militar en Argentina donde jamás se aceptó por ningún actor la existencia de una guerra civil. Una dictadura en Chile, donde los institutos militares defendieron su actuación desde la perspectiva de una "guerra civil", pero dicha línea argumentativa jamás fue tenida en cuenta por las comisiones de la verdad, ni por la justicia chilena o internacional.

En segundo lugar encontramos profundas diferencias desde el origen mediato de las violencias; en Argentina y Chile las concepciones de involucramiento militar en la política desde los años veinte y treinta del siglo XX, pero con una evidente concepción democrática, en periodos anteriores. La ausencia de verdaderas democracias en Centroamérica; la concepción geoestratégica de istmo; fronteras porosas al extremo y consideración tribal de violencia.

En Argentina y Chile la asesoría fue mucho más evidente a través de la CIA y otras agencias de seguridad estatal. Las concepciones doctrinales americanas jamás han influenciado al Cono Sur de influencia militar más europea. En el caso peruano nos encontramos con una situación de inexistencia en los años ochenta de 
una doctrina COIN, unas FFAA solo enfocadas en una guerra convencional, con armamento proveniente de la Unión Soviética en gran medida, pero sin los niveles de alistamiento suficientes.

Por otro lado, la desinstitucionalización militar fue el común denominador en El Salvador, con un nivel de preparación demasiado bajo de sus cuadros y ni qué decir de los soldados. La situación argentina variaría respecto a la existencia de una tradición militar de décadas, impactada por luchas partidistas, luego transformadas en ejes ideológicos con el desencadenamiento de una violencia mucho más sistemática.

En Chile ocurrieron cosas parecidas a las de la Argentina, pero incluso dentro de las mismas Fuerzas y antes del golpe militar como se estudió en la primera parte. El Caso Chileno muestra unos caracteres muy particulares amén del profesionalismo militar, y la influencia de una meta contexto de guerra fría. El caso peruano tiene aristas relacionadas con todos los anteriores casos en una u otra medida, pero mezclados con la existencia de autodefensas campesinas (rondas), que todavía son constitucionales y legales. Los excesos militares de ciertos miembros de la institución castrense se dieron en circunstancias que pueden ser miradas desde dos micro-contextos. Las masacres en lo rural en plena guerra irregular contra los "terrucos" y en el contexto de una guerra sucia a través de los escuadrones de la muerte de Montesinos.

\section{PRINCIPALES ABREVIATURAS Y SIGLAS}

AGN: Academia de Guerra Naval

CANI: Conflicto Armado No Internacional.

CIDH: Comisión Interamericana de Derechos Humanos.

CPI: Corte Penal Internacional.

CORTE IDH: Corte Interamericana de Derechos Humanos.

DADH: Declaración Americana de Derechos Humanos.

DD.HH.: Derechos Humanos

DIDH. Derecho Internacional de los Derechos Humanos.

DIH: Derecho Internacional Humanitario.

ECHR: European Court of Human Rights

ER: Estatuto de Roma.

FF.AA.: Fuerzas Armadas (En otros países)

FF.MM.: Fuerzas Militares. (En Colombia)

ICC: International Criminal Court

IIDH: Instituto Interamericano de Derechos Humanos

MSR: Military System Reform or Military Sector Reform.

OACDDHH: Oficina de la Alta Comisionada de la ONU para los Derechos Humanos.

OCDE: Organización para la Cooperación y el Desarrollo Económico.

OEA: Organización de Estados Americanos. 
OECD: Organisation for Economic Co-operation and Development.

ONU: Organización de Naciones Unidas.

RESDAL: Red de Seguridad y Defensa de América Latina.

SIDH: Sistema Interamericano de Derechos Humanos.

SSR: Security System Reform or Security Sector Reform.

\section{REFERENCIAS}

Academia de Guerra Naval - AGN. (2015, agosto 21). III foro Interamericano sobre Justicia Militar y Derecho Operacional. Recuperado de Acanav.mi.cl

Acosta, J. \& Londoño, M. (2015). Juicio de sustitución: La participación política de excombatientes como desarrollo del marco democrático participativo. En K. \&. Ambos. Justicia de transición y constitución II (pp. 85-116). Bogotá: Temis.

Ambos, K. (2008 b). El marco jurídico de la justicia de transición. Bogotá: Temis.

Ames, R. (2006). Violencia, verdad... ¿ Reconciliación en el Perú? En IIDH. Verdad, justicia y reparación. Desafios para la democracia y la convivencia social (pp. 205-228). Bogotá: IDEA - IIDH.

Aznar, F. (2011b). La ecuación de la guerra. Madrid: Montesinos Ensayos.

Bass, G. (2000). Stay The Hand of Vengeance: The politics of war Crimes Tribunals. Princeton: Princeton University Press.

Berinstain, C. (2006). Reconciliación y democratización en América Latina: Un análisis regional. En IIDH, Verdad, justicia y reparación. Desafios para la democracia y la convivencia social (pp. 53-84). Bogotá: IIDH - IDEA.

Bonilla, O. (2008). Las reformas al sector seguridad en América Latina y el impacto de las amenazas irregulares. En J. Perales. Reforma de las Fuerzas Armadas en América Latina y el impacto de las amenazas irregulares (pp. 15-24). Washington: Woodrow Wilson International Center.

Bosombrio, C. (2008). Las reformas al sector seguridad en América Latina y el impacto de las amenazas irergulares: El caso peruano. En J. Perales. Las reformas al sector seguridad en América Latina y el imapcto de las amenazas iregulares (pp. 59-68). Washington: Woodrow Wilson International Center.

Bouthol, G. (1970). Ganar la paz evitar la guerra. Barcelona: Plaza y Janes.

Brinkerhoff, D. (2005). Rebuilding governance in failed states and post-conflict societies: Core concepts and cross-cutting themes. Public Administration and Development.

Ciurlizza, J. (2005). Las reformas institucionales propuestas por la CVR en el ámbito de la defensa nacional y el orden interno. En C. A. Juristas. La reforma del sector defensa y las relaciones civiles - militares en el Perú (pp. 27-44). Lima: Comisión Andina de Juristas - Ministerio de Defensa. 
Congreso de la República de Perú. (2001, septiembre 28). Denuncia por traición a la patria. Recuperado de www.congreso.gob.pe

Correa, C. (2014). Artículo 63. Competencia y funciones. En C.\&. Steiner. Convención Americana sobre Derechos Humanos (p. 817). Berlin, Bogotá: Konrad Adenuer.

Corte Interamericana de Derechos Humanos. (2001, agosto 31). Caso Comunidad Mayagna (Sumo) Awas Tingni vs Nicaragua. Fondo Reparaciones y Costas. Sentencia del 31 de agosto de 2001. Serie C Número 79.

Corte Interamericana de Derechos Humanos. (2006). Goiburú y otros vs Paraguay. Fondo y Reparaciones y Costas.

Corte Interamericana de Derechos Humanos. (2009, noviembre). Masacre de las Dos Erres Vs. Guatemala.

Corte Interamericana de Derechos Humanos. (2012, octubre). Caso Masacres de El Mozote y lugares aledaños vs. El Salvador. Fondo Reparaciones y Costas.

Cuéllar, B. (2006). Los dos rostros de la verdad salvadoreña. En IIDH. Verdad, justicia y reparación. Desafios para la democracia y la convivencia social (pp. 145-174). Bogotá: IDEA - IIDH.

Cuya, E. (2011). La Justicia Transicional en América Latina: Desarrollo, aplicación, desafios. Recuperado de http://www.menschenrechte.org/lang/es/ strafgerichtsbarkeit/justicia-transicional

CVR. (2003). Informe de la Comisión de la Verdad y la Reconciliación del Perú. Lima.

Dammert, L. (2008). Reformas del sector seguridad. Caso Chile. En J. Perales. Reforma de las Fuerzas Armadas en América Latina y el impacto de las amenazas irregulares (pp. 99-102). Washington: Woodrow Wilson International Center.

De Gamboa, C. (2006). Justicia transicional: Teoría y praxis. Bogotá: Editorial Universidad del Rosario.

Diamint, R. (2008). Defensa, seguridad y Estado de derecho. En J. Perales. Reforma de las Fuerzas Armadas en América Latina y el impacto de las amenazas irregulares (pp. 105-117). Washington: Woodrow Wilson International Center.

Dugard, J. (1999). Dealing With Crimes of a Past Regime. Is Amnesty Still an Option?. Leiden Journal of International Law, vol. 12.

Elster, J. (1998). Coming to terms with the past. A framework for the study of justice in the transition to democracy. S.L: Archives Europeennes de Sociologie.

European Court of Human Rights - ECHR. (2005, february 4). Mamatkulov and Askarov v. Turkey.

International Criminal Court - ICC. (2008, january 18). Situation in the Democratic Republic of Congo in the Case of the Prosecutor v. Thomas Lubanga Dyilo. Decision om Victim's participation. (ICC 01/04/01/06).

Instituto Interamericano de Derechos Humanos - IIDH. (2006). Verdad, justicia y reparación. Desafios para la democracia y la convivencia social. Guía Didactica. San José: IIDH. 
Kritz, N. (1995). Transitional Justice, Volume 2 country studies. Washington: United States Institute of Peace.

Londoño, M. (2014). Las garantías de no repetición en la jurisprudencia interamericana: Derecho internacional y cambios estructurales del Estado. Mexico D.F.: Tirant Lo Blanch.

Machillanda, J. (2010). Del profesionalismo militar a la milicia. Caracas: Italgráfica S.A.

Mack, H. (2006). La reconciliación en Guatemala. Un proceso pendiente. In IIDH, Verdad, Justicia y Reparación. Desafios para la Democracia y la convivencia social. (pp. 175-204). Bogotá: IDEA - IIDH.

Mejía, J. (2015a). Algunos problemas sobre el trasplante conceptual en relación a la justicia para la transición. Bogotá: S.P.

Mejía, J. (2015b). Algunos problemas en torno al informe Verdad, justicia y reparación de la Comisión Interamericana de Derechos Humanos y el caso de la formulación de una justicia para la transición en Colombia. Bogotá: Universidad el Rosario.

O’Donell, G. (1997). Contrapuntos. Ensayos escogidos sobre autoritarismo y democratización. Buenos Aires: Paidos.

OEA. Organización de Estados Americanos.

OECD. (2007). OECD DAC Handbook on Security Sector Reform. (SSR) Supporting Security and Justice. Paris: OECD.

ONU. (2005). Informe de Diane Orentlicher, Experta independiente encargada de actualizar los principios de lucha contra la Impunidad. Ginebra: ONU.

ONU. (2012). The United Nations SSR Perspective. New York: Department of Peacekeeping Operations. Office of rule of law and security institutions.

Orentlicher, D. (1994). Addressing Gross Human Rights Abuses: Punishment and Victim Compensation. In L. \&. Henkin. Human Rights: An Agenda for the Next Century. The American Society of International Law.

Orozco, I. (2002). La postguerra colombiana: divagaciones sobre la venganza, la justicia y la reconciliación. Análisis Político, 46, pp. 78 -99.

Pecaut, D. (2008). Las Farc. ¿Una guerrilla sin fin o sin fines? Bogotá: Norma.

Perales, J. (2008). Reforma de las Fuerzas Armadas en América Latina y el impacto de las amenazas irregulares. Washington: Woodrow Wilson International Center.

Pizarro, E. (2004). Una democracia asediada. Balance y perspectivas del conflicto armado en Colombia. Bogotá: Grupo Editorial Norma.

PNUD. (2009). Reformas recomendadas por Comisiones Internacionales. Hechos del Callejon, pp. 10-11.

Quinche, M. (2014). Control de convencionalidad. Bogotá: Temis.

RESDAL. (2015). Atlas comparativo de la defensa en America Latina y el Caribe. Buenos Aíres: RESDAL. 
Rico, J. (2000). Proyecto de seguridad ciudadana en Centroamérica. Informe Final de Evaluación. San José: Instituto Interamericano de Derechos Humanos República China.

Schultze, K. (2005). Pacificación y poder civil en Centroamérica. las relaciones civico - militares en El Salvador, Guatemala y Nicaragua en el posconflicto. Bogotá: Norma.

Serra, N. (2008). La transición militar. Reflexiones en torno a la reforma democrática de las Fuerzas Armadas. Barcelona: Random House Mondadori S.A.

Steiner, C., \& Uribe, P. (2014). Convención Américana sobre Derechos Humanos. Berlin - Bogotá: Konrad Adenuer.

Tapattá, P. (2006). El pasado, un tema central del presente. En IIDH. Verdad, Justicia y Reparación. Desafios para la democracia y la convivencia social (pp. 85-114). Bogotá: IDEA - IIDH.

Toro, M. (2003). La gobernanza internacional. Una propuesta para gestionar la globalización. Mexico: Centro de Estudios Internacionales.

UNASUR. La Unión de Naciones Suramericanas

Uprimny, R. (Dir.). (2006). ¿Justicia transicional sin transición? verdad, justicia y reparación para Colombia. Bogotá D.C.: Dejusticia. 